\title{
MISMIDAD, RELACIÓN Y FICCIÓN. UNA ONTOLOGÍA SINCATEGOREMÁTICA DE LA MODERNA COMUNIDAD HISPANOHABLANTE
}

Juan Antonio González de Requena Farré 


\title{
MISMIDAD, RELACIÓN Y FICCIÓN. UNA ONTOLOGÍA SINCATEGOREMÁTICA DE LA MODERNA COMUNIDAD HISPANOHABLANTE*
}

\begin{abstract}
Resumen: A través de su historia, la teoría filosófica ha propuesto distintos repertorios de categorías que dieran cuenta de la estructura última de la realidad; sin embargo, para caracterizar los sentidos fundamentales del ser, el discurso de la Filosofía no ha dejado de emplear determinantes, conectores y otras expresiones formales de relación o modo sin un significado sustantivo. Este artículo realiza un análisis de contenido de los sentidos en que la comunidad hispanohablante emplea expresiones como per se, entre o como si, relacionadas con la categorización de la mismidad, la relación o la ficción contrafáctica.
\end{abstract}

Palabras clave: categorías, expresiones sincategoremáticas, per se, entre, como si.

\section{SELFNESS, RELATIONSHIP AND FICTION. A SYNCATEGOREMATIC ONTOLOGY OF MODERN SPANISH SPEAKING COMMUNITY}

\begin{abstract}
Through its history, philosophical theory has proposed different repertoires of categories to establish the ultimate structure of reality; however, to characterize the fundamental meanings of being, the discourse of Philosophy has not stopped using determinants, connectors and other expressions of relationship without substantive meaning. This article performs a historical analysis of the sense in which Spanish speaking community uses expressions like per se, between or as if, related to the categorization of selfness, relationship or counterfactual fiction.
\end{abstract}

Keywords: Categories, syncategorematic expressions, per se, between, as if.

Fecha de recepción: Junio 12 de 2015

Fecha de aceptación: Septiembre 9 de 2015

Forma de citar: González, J. (2015). "Mismidad, relación y ficción. Una ontología sincategoremática de la moderna comunidad hispanohablante". Revista Filosofía UIS. 14 (2). pp. 47-67.

Juan Antonio González de Requena Farré: Doctor en Filosofía (Universidad Complutense de Madrid), docente de la Universidad Austral de Chile.

Correo electrónico: jgonzalez@spm.uach.cl

*Artículo de investigación. 


\section{MISMIDAD, RELACIÓN Y FICCIÓN. UNA ONTOLOGÍA SINCATEGOREMÁTICA DE LA MODERNA COMUNIDAD HISPANOHABLANTE}

\section{La problematización de las categorías en la tradición filosófica}

A través de la historia del pensamiento occidental cabe reconocer todo un repertorio de distinciones decisivas que articulan los significados primordiales del ser, delimitan las formas generales en que algo es conceptualizado, y permiten identificar qué es lo que hay en última instancia. En ese sentido, la tradición filosófica ha introducido distintos conjuntos de categorías y marcos categoriales, diferentes géneros supremos, predicamentos, así como conceptos puros, trascendentales, fundamentales o básicos, con la pretensión de describir comprehensivamente la estructura última o el entramado de fondo de nuestro pensamiento del ser. No hay posicionamiento metafísico o decisión comprehensiva de qué es lo que hay y cómo se nos manifiesta, sin que se esboce algún repertorio categorial o se determinen las categorías fundamentales del ser de cuanto existe. Estas categorías decisivas de la filosofía occidental no se han concebido simplemente como tipos de expresiones lingüísticas o construcciones gramaticales, pues se les ha atribuido cierto alcance lógico (determinan las formas más universales de la conceptualización y predicación), así como un marcado compromiso ontológico (ya que conciernen a la articulación real del ser). De ese modo, las categorías no solo han sido tradicionalmente comprendidas como los géneros supremos o las clases más generales de entidades que cabe concebir, sino que, además, han incorporado toda una serie de requisitos lógicos y ontológicos. Se ha señalado que un repertorio de categorías idealmente formulado debería ser exhaustivo (de manera que toda entidad caiga en alguna categoría) y habría de forjar categorías mutuamente excluyentes (de modo que ninguna entidad caiga en varias categorías) (Butcharov, 2009). También, se ha insistido en que las categorías básicas (esto es, las clases generales de entidades o géneros del ser) deberían determinar a priori — de modo universal y necesario - tanto las condiciones distintivas de 
existencia cuanto las condiciones de identidad de sus integrantes, logrando así individualizarse con precisión y agotar la totalidad de lo existente. Y, además, se ha remarcado el carácter jerárquicamente organizado de las categorías, las cuales se subordinan unas a otras — según el grado de generalidad de las entidades que comprenden- y caen bajo alguna categoría más fundamental (Lowe, 2006, pp. 6-7). Por otra parte, se ha argumentado que nuestros repertorios de categorías básicas conforman auténticos marcos categoriales, que cumplen ciertas condiciones lógicas y existenciales, a saber: distribuyen consistentemente a la pluralidad de las cosas en los géneros últimos no vacíos designados por cada categoría; asocian cada género último a ciertos principios categoriales constitutivos (con los que se deciden los atributos o condiciones generales de aplicación de la categoría) y a ciertos principios categoriales de individuación (que permiten reconocer un atributo distintivo de cada entidad particular perteneciente a la categoría); pero, además, dependen de cierta concepción de la Lógica, con sus nociones propias de implicación y consistencia. Y, con frecuencia, se añade cierta pretensión de unicidad, como si el marco categorial que da forma a nuestro pensamiento del ser fuera el único posible, universal y necesario (Körner, 1970).

Ya en los diálogos de Platón se encuentra la decidida comprensión del pensamiento del ser como una aprehensión intelectual de las ideas últimas o formas esenciales; pero también hallamos una determinación de los géneros supremos, que en el Sofista (2007, 254 d-e) se reducen a cinco: el ser, el reposo, el movimiento, la identidad y la diferencia. Sin embargo, será Aristóteles quien le dé una formulación adecuada a una doctrina lógica-ontológica de las categorías, como modos primordiales en que el ser se enuncia o aquellos sentidos más generales del ser que pueden predicarse de las entidades. Tanto en Categorías como en Metafísica, Aristóteles distingue diferentes acepciones fundamentales del ser, entre las que figuran la sustancia, la cualidad, la cantidad, la relación, la acción, la pasión, el lugar, el tiempo, la posición en que se está y la posesión que se tiene (Aristóteles, 2000 y 1999). Por cierto, las interpretaciones de las categorías aristotélicas han puesto de manifiesto cierta tensión entre el sentido gramatical de las categorías como los modos más generales de enunciar predicativamente, el sentido lógico de las categorías como formas universales de conceptualizar las entidades y, por último, el sentido ontológico de las categorías como significados fundamentales o géneros supremos en que se articula el ser de las entidades reales. Ciertamente, algunos intérpretes han considerado discursivamente a las categorías en tanto que figuras plurales de la predicación — que enuncian las múltiples significaciones del ser, tal y como se expresan en el discurso predicativo, a través de la cópula del verbo ser entre un sujeto y ciertos predicados - , o como enunciación de una respuesta a los distintos tipos fundamentales de pregunta (por el qué, el cómo, el cuánto, el dónde, el cuándo, etc.) (Aubenque, 1974). Sin embargo, lo cierto es que la tradición y algunas lecturas modernas privilegian el sentido ontológico fundamental de las categorías o predicamentos, como si se tratase de conceptos reales de esos géneros supremos que pueden predicarse de 
las sustancias primeras o las entidades determinadas. $Y$ aunque se haya señalado cierto carácter fragmentario, disperso, rapsódico y carente de criterio en las categorías aristotélicas, también se ha podido ver en ellas una rigurosa deducción de los sentidos fundamentales o géneros supremos del ser. Cabría distinguir un ser en sentido absoluto, como el de la substancia o el de los accidentes; entre los accidentes, algunos serían absolutos y los otros solo relacionales; de los accidentes absolutos, algunos serían inherentes (como la cantidad o la cualidad), otros constituirían operaciones (como el hacer o el padecer) y otros serían circunstanciales (como el lugar o el tiempo) (Brentano, 2007).

Así como la concepción aristotélica tradicional de las categorías siguió una vía lógico-ontológica comprometida con los sentidos últimos del ser, cabe reconocer un enfoque netamente lógico-epistemológico en la teoría kantiana de las categorías. Cuando, en la Crítica de la razón pura, Kant se propone establecer las condiciones de posibilidad del conocimiento objetivamente válido, introduce un repertorio de categorías que constituyen los conceptos puros originarios bajo los cuales el entendimiento puede concebir a priori — de modo universal y necesario - la unificación de lo múltiple empíricamente dado en la intuición. En ese sentido, las categorías kantianas subsumen lógicamente las formas puras en que nuestros juicios llevan a cabo la síntesis de lo múltiple; constituyen los conceptos trascendentales de las distintas funciones lógicas del juicio, esto es, de los distintos modos a priori en que se puede llevar a cabo la síntesis conceptual de lo diverso dado en la intuición (al atribuir un predicado a un sujeto, o ciertas propiedades a los objetos). Como reglas lógico-epistemológicas para la producción del conocimiento objetivamente válido y para la representación a priori del objeto en general, las categorías kantianas se fundamentan en la propia unificación representacional que produce nuestro conocimiento, así como en el principio supremo de tal unificación, a saber: la unidad trascendental de la apercepción, ese "yo pienso" o acto de conciencia que acompaña originariamente —como foco unificador - a la representación de cualquier objeto. Kant establece cuatro categorías fundamentales — la cantidad, la cualidad, la relación y la modalidad—, que subsumen los conceptos puros de los distintos tipos de juicios lógicos: en la medida en que podemos construir juicios universales, particulares o singulares, todo lo que se da lo hace con cierta cantidad o en cierta magnitud (la unidad, la pluralidad o la totalidad); de otros tipos de juicio (afirmativos, negativos, infinitos, categóricos, hipotéticos, disyuntivos, problemáticos, asertóricos o apodícticos) se sigue que no podemos concebir lo dado sino bajo cierta cualidad o grado de realidad (la realidad, la negación o la limitación), bajo ciertas relaciones (la de sustancia y accidentes, la relación causal o la de reciprocidad) y bajo cierta modalidad (como posible, realmente existente o necesario). Ciertamente, las categorías kantianas constituyen el andamiaje lógico-epistemológico o el esquema conceptual trascendental que hace posible el ordenamiento de la experiencia, sin que las categorías mismas estén dadas en la experiencia. Desde ese punto de vista, las categorías kantianas no tienen alcance ontológico como géneros supremos que 
signifiquen lo que las cosas sean en sí mismas o su ser último incondicionado. Sin embargo, aunque las categorías constituyen conceptos puros del entendimiento o modos a priori de unificar lo múltiple, no tienen sentido sino en la medida en que se aplican a la unificación representacional de lo dado empíricamente en la intuición (Kant, 2002). El alcance fundamentalmente lógico-epistemológico de las categorías kantianas ha sido señalado por algunos comentaristas, quienes han visto en las categorías un marco constructivo de los objetos de conocimiento o un ordenamiento racional fundamental de nuestra actividad intelectual, formulado como un repertorio sistemático de las modalidades puras del juicio, esto es, de las condiciones de posibilidad del acto lógico que lleva a cabo el entrelazamiento de lo múltiple. En ese sentido, las categorías le conferirían validez a priori a nuestro conocimiento del objeto en general, haciendo posible la universalidad y necesidad de la ciencia físico-matemática (Cassirer, 1993). En otros casos, los intérpretes han reconocido en la Crítica de la razón pura un ejercicio de fundamentación metafísica (y no simplemente una teoría del conocimiento), consistente en delimitar la posibilidad del conocimiento ontológico como un representar referido al ente dado como objeto; desde esa perspectiva, las categorías kantianas no serían tanto conceptos puros de los juicios lógicos, cuanto conceptos reflectantes que permiten llevar a cabo cierta síntesis ontológica: la unificación representativa de lo ente, por parte de un conocedor finito cuya actividad originaria consiste en la objetivación y en la representación de lo contrapuesto como objeto (Heidegger, 1996).

A los enfoques lógico-ontológico y lógico-epistemológico de las categorías, la Filosofía Analítica contemporánea ha sumado un punto de vista lógico-lingüístico sobre nuestro empleo de los conceptos básicos. Si bien se sustenta en cierta metafísica descriptiva —asociada al análisis conceptual de los rasgos más generales de nuestra estructura conceptual—, y aunque se sirve del análisis lógico — para establecer los tipos lógicos y funciones lógicas de las expresiones contenidas en las proposiciones-, el análisis lógico-lingüístico de las categorías se centra primordialmente en la descripción gramatical de aquellas palabras comúnmente empleadas que suministran los conceptos fundamentales a partir de los cuales se elaboran los vocabularios conceptuales más sofisticados y especializados (Strawson, 1996, pp. 9-11). En ese sentido, Gilbert Ryle (2009) pudo desarrollar una teoría de las categorías que no registra simplemente un catálogo restrictivo de los tipos de predicados últimos (como la teoría aristotélica de las categorías), ni se limita a formular parcialmente los conceptos puros de algunas formas lógicas del juicio, a partir del supuesto epistemológico —o la proyección metapsicológicade que la naturaleza está regulada precisamente por esas formas lógicas y de que conocemos a priori esa regulación (como ocurre en la teoría kantiana). La teoría de las categorías propuesta por Ryle no pretende acotar escolásticamente una tabla definitiva de categorías últimas, sino que se sustenta en la introducción de un criterio para formular la homogeneidad o heterogeneidad de los tipos de expresión gramatical $-y$, básicamente, de los tipos de factores enunciativos que 
conforman las funciones elementales de nuestras proposiciones-, con el propósito de reconocer los errores categoriales que se producen cuando confundimos tipos lógico-gramaticales de expresiones. El criterio propuesto por Ryle para distinguir tipos de categorías consiste en que una determinada expresión gramatical con una función lógica específica, o sea, un factor proposicional —entendido como elemento del sentido del enunciado- pueda completar cierto esquema de frase, o pueda reemplazar a otra expresión equivalente sin que se genere un absurdo o sinsentido. Así, pues, se incurre en un error categorial cuando se emplean como equivalentes expresiones gramaticales de tipos lógicos diferentes o que realizan distintos factores proposicionales; por ejemplo, si alguien afirma que va a usar su par de guantes y el guante derecho, reconocemos el empleo de dos factores proposicionales que realizan tipos lógicos distintos, y no pueden ser unidos en conjunción ni reemplazarse en un esquema enunciativo como $A$ y $B$, o bien como A o B (Ryle, 2009; 2005, p. 36). Algunas críticas al criterio de Ryle han señalado que la denuncia de los errores categoriales presupone un conocimiento de las categorías a las cuales debería asignarse, correctamente, cierta expresión gramatical (Alemán, 1985, pp. 96-99), y también se ha argumentado que el criterio de sustitución sin absurdo solo permite establecer cuándo dos expresiones gramaticales son de diferentes categorías, pero no cuándo son de la misma categoría (Smart, 1953). No obstante, cabe señalar que, a diferencia de lo que ocurre en los lenguajes simbólicos de la Lógica, en el lenguaje natural no existe un repertorio formalizado de tipos lógicos que se puedan distinguir con exactitud y asignar a clases equivalentes; más bien hallamos empleos superpuestos y flexibles de las expresiones gramaticales prototípicas, aunque habitualmente podemos detectar cuándo se producen absurdos. En ese sentido, para la Filosofía Analítica contemporánea, el análisis conceptual de nuestras categorías básicas parece conducir a la descripción sistemática de la estructura conceptual, esto es de las características generales y de las conexiones que existen entre los conceptos que estructuran nuestra concepción del mundo en el discurso ordinario y en nuestras formas de vida (conceptos como identidad, cambio, verdad, conocimiento, acción, etc.). De ahí que Strawson (1997, p. 69) haya podido caracterizar laxamente las categorías como esos tipos de conceptos básicos o conceptos generales, omnipresentes e irreducibles, que conforman la estructura conceptual, esto es, el marco de nuestro pensamiento y del discurso ordinario (también presupuesto por las disciplinas especializadas), a partir del cual se forja nuestra visión del mundo.

\section{Los nexos de sentido de las expresiones sincategoremáticas, en el lenguaje filosófico y en el discurso cotidiano}

Como Ryle (2009) ha observado, la tradicional discusión filosófica sobre las categorías básicas frecuentemente estuvo enrarecida por el presupuesto de que los tipos últimos de predicados consistirían en términos aislados (como las expresiones nominativas de los sujetos y las expresiones predicativas) unidos por la cópula del 
verbo ser. Eso sí, Ryle omite que la Filosofía antigua y medieval mantuvo cierta distinción aristotélica entre los predicamentos o categorías últimas del ser y, de otro lado, los predicables o categoremas, que pueden ser atribuidos lógicamente al sujeto y definen la esencia de lo denotado (como el género, la especie, la diferencia, lo propio y el accidente). El caso es que la Lógica medieval formuló explícitamente la distinción entre los términos categoremáticos (que tienen un significado propio por sí mismos y aisladamente) y, por otra parte, los términos sincategoremáticos (expresiones lógicas como los conectores o los cuantificadores, y expresiones gramaticales como los artículos, preposiciones, conjunciones, adjetivos o adverbios) que solo adquieren significado cuando acompañan a algún categorema. De hecho, pensadores medievales como Shyreswood, Ockham o Buridán comparten la idea de que los enunciados contienen tanto partes primarias que tienen un objeto propio y una significación determinada y fija (los términos categoremáticos), cuanto partes secundarias que simplemente determinan a las primarias y desempeñan ciertas funciones junto a los categoremas, sin tener un significado determinado y fijo. Los categoremas constituirían la materia del enunciado, en tanto que los términos sincategoremáticos solo introducen determinaciones formales en la lógica del enunciado (Bochenski, 1985, pp. 170171). Sin embargo, _ como ha argumentado Ryle (2009)_ la clasificación de los tipos de expresiones gramaticales que realicen una misma función proposicional depende de la clasificación de la forma lógica de las proposiciones y, por tanto, del análisis de las expresiones sincategoremáticas que introducen nexos formales y relaciones estructurales. En ese sentido, cualquier teoría de las categorías habría de incorporar también una teoría de los términos sincategoremáticos. Ahora bien, tomarse en serio el papel que en la enunciación juegan los términos sincategoremáticos no implica solo explicitar las distintas formas lógicas que enmarcan la función proposicional de nuestras expresiones gramaticales; y es que las determinaciones sincategoremáticas tienen cierta relevancia ontológica, en la medida en que permiten articular el entramado de relaciones y conexiones que caracterizan los significados del ser y el modo de darse de las entidades.

No en vano, a través de la historia de la Filosofía occidental, no ha sido posible definir los géneros supremos del ser o las categorías básicas en que el ser se significa, salvo por medio de términos categoremáticos que tuvieran como significado fijo al objeto denotado; asimismo, para caracterizar los sentidos básicos del ser ha sido preciso introducir términos sincategoremáticos (frases preposicionales, locuciones adverbiales, etc.), o sea, todo un repertorio de expresiones determinativas de los modos en que las entidades son. Ya en los diálogos de Platón (particularmente en el Parménides), las ideas que constituyen el verdadero aspecto de las cosas se caracterizan como las formas en sí y como aquello que es en sí y por sí mismo ( $\alpha$ đò $\kappa \alpha \vartheta^{\prime} \alpha$ avó); se trataría de acceder a lo esencial de las cosas en sí mismas, a su identidad per se o su aspecto objetivo, abstractamente aislado de la inestabilidad fluctuante del devenir concreto (Havelock, 2002, pp. 203-217).

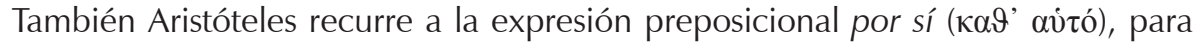


caracterizar las significaciones fundamentales del ser (tal y como se expresan en los modos de predicar, o sea en las distintas categorías), por oposición a aquello que es meramente accidental; según Aristóteles, por sí se dice de la esencia de cada cosa (lo que es por sí misma) y de las determinaciones que definen la esencia de algo, pero también se dice del sujeto, de lo que no tiene otra causa y de aquellas propiedades de una entidad que existen exclusivamente en una entidad separada (que existe por sí misma) (Aristóteles, 2000, 1022a). Al comentar los escritos de Aristóteles sobre las categorías, Porfirio (1999, pp. 43-44) estableció que existe un tipo de diferencia per se, esto es un predicable que permite definir lo que las cosas sean y que se caracteriza por resultar inseparable de lo que algo es, de modo que constituiría un atributo esencial y no meramente accidental. En el pensamiento escolástico, la discusión sobre el sentido del ser por sí mismo se profundizó, y Santo Tomás pudo definir la sustancia como aquello que es per se, esto es, como aquello que no es en otro o no es modificación de otra cosa (per aliud), de manera que constituye algo que subsiste autónomamente, una esencia que es identificable como algo en sí y por sí mismo (Copleston, 2000, p. 90; Beuchot, 1991). Como se puede apreciar, el pensamiento antiguo y medieval aparece tensionado por una concepción del ser per se en tanto que ser en sí mismo (como la inherencia que define a la esencia) o en tanto que ser por sí mismo (como la subsistencia autónoma).

Algunas filosofías modernas y contemporáneas también exhiben esta paradoja de que no se pueda concebir el sentido sustantivo del ser, sino a través de expresiones determinativas. Pero, además, cabe considerar que el pensamiento moderno y contemporáneo ha radicalizado la diferencia entre los sentidos del ser como inherencia esencial de lo que es en sí y, por otra parte, como autonomía de lo que subsiste por sí mismo de modo autónomo. La Filosofía hegeliana es particularmente pródiga en el empleo de expresiones preposicionales que designan los distintos momentos en el despliegue del ser hasta llegar a concebirse per se, o sea, en sí y por sí mismo. Hegel caracteriza a la esencia inmediatamente dada —indeterminada, abstracta y aislada frente a algo otro- como el simple ser en sí mismo (An-sich-sein) que aún no ha sido concebido, en tanto que emplea la expresión para sí (Für-sich-sein) cuando da cuenta del momento reflexivo de la mediación de lo dado inmediatamente y de la autorreferencia del pensamiento del ser. Sin embargo, el cumplimiento pleno del pensamiento del ser solo se daría bajo la figura del ser en sí y para sí mismo, como reapropiación reflexiva de lo dado y correspondencia entre la esencia y el concepto, esto es, como actualización consumada de la autoconciencia (Hegel, 1985; Hyppolite, 1974). En la Filosofía contemporánea, también Sartre (1982) se ha servido de las frases preposicionales en sí (en soi) y para sí (pour soi), a la hora de dar cuenta de la tensión que atraviesa la realidad humana: el ser en sí consiste en la muda presencia actual de las cosas dadas, y designa la facticidad y opacidad absurda de lo que hay sin cuestionamiento posible ni consciencia alguna; por otra parte, el ser para sí caracteriza la autoconconciencia del existente, que lleva a cabo la 
nihilización de lo dado y resuelve libremente sus propias opciones, pues se trata de un ser que cuestiona su propio ser, así como es trascendencia que esboza su propio proyecto existencial al volcarse intencionalmente en el mundo.

En todo caso, la Filosofía contemporánea parece haber asumido decididamente el aspecto del ser como conexión, relación o interacción, más allá de la tentación de cosificar el ser como la cosa sustantivamente dada o como el repertorio de los entes objetivados. Hay toda una serie de filosofías del entre, que caracterizan la condición de intervalo del ser de lo que hay, así como la apertura, exterioridad y copertenencia de los existentes. En ese sentido, Heidegger (1960) nos invitó a hacernos cargo del entre (Zwischen), como estado de apertura que caracteriza al existir y como ámbito en que tiene lugar el desocultamiento y el ocultamiento del ser; pero, además, Heidegger señaló lo decisivo que resulta atender al entre que se abre entre los hombres y las cosas, en vez de conformarnos con la representación de las cosas contrapuestas como objetos (Heidegger, 1985, p. 186), e, incluso, invocó el entre como ese umbral o intervalo de la diferencia, que nos expone a la apertura e intimidad del ser — en el inter-medio del mundo y las cosas-, y nos convoca a corresponder al Ilamado irrevocable de la diferencia (Heidegger, 1987). En otras perspectivas de la Filosofía contemporánea, se ha apelado al entre, para dar cuenta de la condición intersubjetiva y relacional del ser humano. En ese sentido, Buber (1967) señala el ámbito del entre como el lugar ontológico de efectiva realización de la existencia humana, pues solo en el entre se da la apertura de un ámbito común de encuentro interhumano, de manera que resulta posible la relación auténtica entre un yo y un tú, así como la comunicación dialógica con otro ser y el estar dos personas en recíproca presencia. En el caso de Hannah Arendt (1997), el entre permite pensar el ámbito constitutivo de la política, que no es otro que la relación entre los seres humanos y la interacción de la pluralidad de los humanos sumamente diversos, que han de estar juntos, distinguirse de los demás, actuar conjuntamente y organizar su convivencia plural los unos con los otros. Actualmente, en filósofos como William Desmond encontramos intentos de construir una ontología del entre (between) y una lógica de lo intermedio, que se haga cargo de la porosidad del ser, de las articulaciones e intermediaciones del ser, tal y como se manifiesta en la condición metafísica intermedia del ser humano (siempre dividido entre la determinación y la indeterminación, expuesto a la apertura plurívoca del ser, convocado en una relación no totalizable con las cosas e involucrado en una pluralidad de intermediaciones irreducibles). Según Desmond (2008), se trata de un entre que abre el espacio para la donación ontológica de la diferencia y permite el entrejuego de la identidad y la alteridad, así como sobredetermina nuestra autodeterminación y nos interpela éticamente a la comparecencia de la alteridad; pero también es un estar entre que posibilita la experiencia porosa de lo que excede nuestra finitud, de manera que apunta a cierta trascendencia a través nuestra inmanencia, y marca una brecha hiperbólica entre la inmanencia y la trascendencia religiosa en algo otro. 
Si bien podría considerarse que la comprensión del ser como relación e intermediación involucra cierta desustancialización de lo que hay, existe una forma más decidida de socavar la idea de que la realidad tiene una estructura fija estable y de cuestionar la categorización del ser como un repertorio definido de modos de darse de los entes, a saber: el reconocimiento de la ficción como un modo de ser decisivo. El ficcionalismo de Hans Vaihinger (1924) involucra una apuesta semejante por entender las categorías humanas y los conceptos generales como simples construcciones intelectuales artificiales, que simplemente condensan semejanzas entre particulares, y, aunque no suministran información sobre la estructura última de la realidad, tienen un valor eminentemente práctico como instrumentos de autopreservación, adaptación funcional y orientación mundana. Según Vaihinger, el repertorio de ficciones que constituyen la realidad humana comprende los dominios del pensamiento y discurso cotidiano, tanto como las construcciones intelectuales de la ciencia, el derecho, la política, la Filosofía, la religión y, obviamente, las ficciones estéticas del arte; abarca esquemas y modelos, clasificaciones artificiales, paradigmas científicos, figuras retóricas, ideales, utopías, arquetipos imaginarios, analogías simbólicas, ficciones jurídicas, personificaciones, ficciones heurísticas, transferencias o extrapolaciones de modelos, generalizaciones abstractas e, incluso, ideas como la de infinito. Lo característico de estas ficciones consiste en que contradicen la realidad —e incluso pueden auto-contradecirse-, son revisables y corregibles, afirman expresamente cierta conciencia de ficcionalidad y se sostienen en la conveniencia para la vida (a través de rendimientos epistemológicos, éticos y espirituales); pero, además, están expuestas a constantes desplazamientos ideacionales que transforman las construcciones mentales de la ficción en hipótesis probables, a las hipótesis en dogmas y viceversa. Cuando explora la forma lingüística de la ficción, Vaihinger no solo destaca la importancia que tienen los conectores, sino que además recurre a una construcción sincategoremática, para expresar la estructura de la ficción: la expresión como si (Als Ob). El nexo como si incorpora un adverbio comparativo y una conjunción condicional, de manera que la comparación introduce una analogía ficcional, y el condicional aporta un sentido contrafáctico y virtual; se trata, pues, del enunciado de una eventual inclusión bajo asunciones irreales e introduce una fórmula en que lo dado específicamente se compara con algo cuya imposibilidad se admite al mismo tiempo, de manera que se induce a tratarlo como ficción (Vaihinger, 1924, pp. 91-94).

En todo caso, aunque parezca idiosincrático y plenamente original como decisión del sentido del ser, el empleo que los filósofos realizan de expresiones sincategoremáticas (como en sí, por sí, para sí, como si, etc.) resulta deudor de la gramática propia del lenguaje natural en que el pensador concibe lo que hay. Y el trabajo del traductor pasa por restituir los nexos de sentido de cierto idioma natal del pensador, sirviéndose de los recursos gramaticales del propio lenguaje natural. No en vano, la forma de traducir expresiones como $\alpha \alpha \vartheta^{\prime} \alpha$ avó, per se o Für-sich-sein, genera conflictos interpretativos y es una auténtica decisión filosófica 
sobre el sentido de lo que hay, que frecuentemente requiere una justificación por parte del traductor. En ese sentido, la traducción filosófica ha de servirse de los nexos gramaticales de que dispone el idioma español, con sus distintos matices de sentido: las construcciones preposicionales en sí, por sí o para sí; la expresión comparativa como si, etc. Las distintas construcciones preposicionales con el pronombre reflexivo de tercera persona sí introducen un matiz de auto-referencia - o autidad - en la enunciación, en la medida en que el sujeto antecedente a que el pronombre sí refiere suele ser el mismo objeto de la acción denotada en el verbo o del grupo nominal al cual determinan, y este efecto se acrecienta cuando a la expresión preposicional se le añade el adjetivo mismo. En el caso de la preposición en, denota ubicación, pero el grupo preposicional en sí incorpora un matiz de autocontención o inherencia; la preposición por remarca la agencia, de manera que la expresión preposicional por sí introduce un sentido de iniciativa propia, independencia o autosuficiencia; para señala finalidad o propósito, de modo que la construcción para sí enfatiza un sentido auto-télico, autorreferencial y de autorreflexión; con denota una relación de compañía y, en el caso de la expresión compuesta consigo, incorpora un matiz de intimidad. La preposición entre denota localización entre límites, aunque el grupo preposicional entre sí expresa una relación múltiple o recíproca. La expresión comparativa como si, integrada por el adverbio relativo como y la conjunción condicional si suele introducir en español una oración subordinada con un verbo en subjuntivo, que refiere un contenido hipotético y habitualmente contrafáctico (Real Academia Española, 2010). En fin, podría conformarse un repertorio categorial — parcial y fragmentario- de los nexos de sentido introducidos por algunas expresiones sincategoremáticas, a partir de la propia gramática de la lengua natural (que recoge los usos habituales del discurso y cristaliza la comprensión lingüística de los hablantes): el ser en sí se asociaría a la categoría de inherencia; el ser por sí, a la categoría de auto-subsistencia o independencia; el ser para sí, a la categoría de auto-referencia o autorreflexión; el ser consigo, a la categoría de intimidad; el ser entre sí a la categoría de comunidad o relación; el ser como si, a la categoría de contrafactualidad o ficción. A diferencia de las categorías filosóficas tradicionales, estos modos de categorización implícitos en la gramática son más flexibles y revisables, no solo por ir acompañados de los infaltables contraejemplos particulares surgidos de los usos lingüísticos concretos, sino también porque no tienen una relación jerárquica entre sí, ni presuponen una estructuración lógica del lenguaje, con clases exhaustivas y excluyentes. Como se puede apreciar, los nexos de sentido de la gramática idiomática son más sofisticados, flexibles y diversos que los repertorios categoriales fijos y determinados, con los cuales algunos filósofos tratan de encuadrar la estructura última de cuanto hay. 


\section{Un análisis de contenido de los usos de algunas expresiones sincategoremáticas en la comunidad hispanohablante moderna}

Con el propósito de explorar ciertas transformaciones en el empleo de algunas expresiones sincategoremáticas con relevancia filosófica (en sí mismo, para sí mismo, por sí mismo, consigo mismo —se añadió el adjetivo mismo para acotar los usos pertinentes- y, además, entre sí y como si), se realizó un análisis de contenido de los usos de dichos términos en el lenguaje natural. Se optó por el análisis de contenido, puesto que es un método que permite reconocer frecuencias temáticas o funcionales en textos, por medio de procedimientos sistemáticos y confiables, para poder formular inferencias válidas sobre el contexto de producción y recepción comunicativos (Bardin, 1996).

\section{Muestra}

Se tomó como muestra de referencia la totalidad de los textos contenidos en el Corpus Diacrónico del Español (CORDE) de la Real Academia de la Lengua Española, entre 1500 y 1950 (RAE, 2015). Se trata de un corpus compuesto por documentos procedentes tanto de España como de Hispanoamérica, y que representa distintos medios (libros y prensa), temáticas (historia, religión, sociedad, derecho, etc.) y géneros (novelas, cartas, ensayos, códigos, etc.). Como se aprecia en la Tabla 1, se segmentó la muestra en periodos de cien años.

Tabla 1. Composición de la muestra

\begin{tabular}{cllllll}
\hline & $1500-1600$ & $1601-1700$ & $1701-1800$ & $1801-1900$ & $1901-1950$ & total \\
\hline documentos & 6144 & 3486 & 3179 & 3178 & 4548 & 20535 \\
palabras & 52178460 & 36386678 & 14490011 & 43398647 & 35300859 & 181754655 \\
\hline
\end{tabular}

Fuente: elaboración propia.

\section{Procedimiento}

Se registraron las frecuencias de cada expresión por siglo (con sus distintas opciones de género y número, en el caso de en sí mismo, por sí mismo, para sí mismo y consigo mismo, así como con las variantes arcaicas formadas con si o mesmo). Para poder comparar las frecuencias de cada expresión se ponderaron con el total de palabras de cada periodo, y también se determinó si existían diferencias significativas entre las frecuencias relativas por siglo, mediante el estadístico Chi cuadrado. 


\section{Resultados}

Al considerar la frecuencia de cada uno de las expresiones sincategoremáticas analizadas, se observa que, en los totales entre 1500 y 1950, predomina el empleo de la fórmula comparativa ficcional como si, seguida por las construcciones preposicionales entre sí y por sí mismo, que denotan relación e independencia, respectivamente; la forma menos empleada es para sí (indicativa de autorreflexión o auto-referencia) tal como se aprecia en la Tabla 2.

Tabla 2. Frecuencia de cada una de las expresiones sincategoremáticas analizadas

\begin{tabular}{lllllll}
\hline & $1500-1600$ & $1601-1700$ & $1701-1800$ & $1801-1900$ & $1901-1950$ & total \\
\hline en sí mismo & 656 & 363 & 150 & 608 & 797 & 2574 \\
por sí mismo & 679 & 371 & 479 & 1072 & 1027 & 3628 \\
para sí mismo & 140 & 51 & 14 & 53 & 69 & 327 \\
consigo mismo & 248 & 103 & 35 & 370 & 291 & 1047 \\
entre sí & 3349 & 1507 & 846 & 2410 & 1888 & 10000 \\
como si & 8013 & 6143 & 1501 & 8315 & 8052 & 32024 \\
\hline
\end{tabular}

Fuente: elaboración propia.

Aunque la expresión comparativa ficcional como si predomina en todos los periodos, se observa una disminución de su empleo en el siglo XVIII, con respecto a los siglos anteriores, y un aumento en el siglo XIX, hasta alcanzar su máximo en la primera mitad del siglo XX. Puede afirmarse, pues, que la ficcionalización ha alcanzado su máxima cota al cabo de la modernidad.

Gráfico 1. Frecuencia de empleo de la expresión comparativa contrafáctica "como si" entre 1500 y 1950, por cada millón de palabras

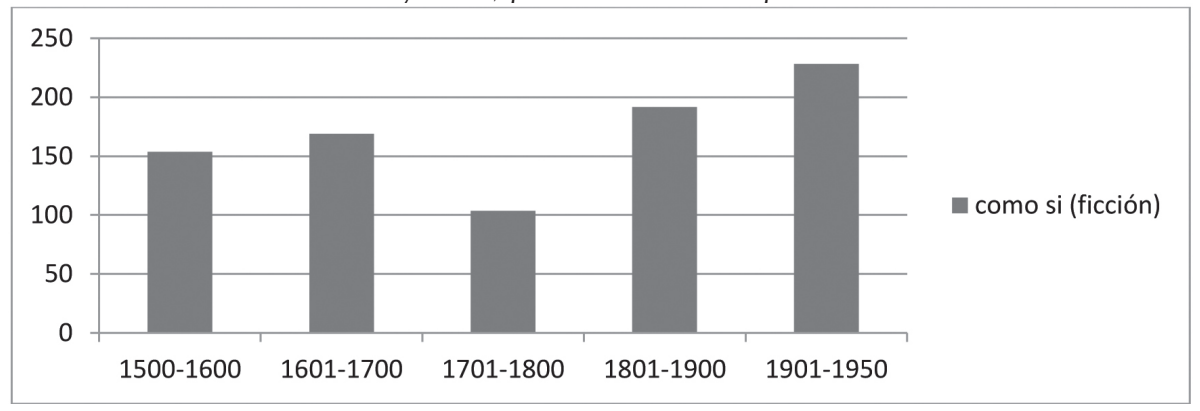

Fuente: elaboración propia.

Dentro del conjunto de las expresiones preposicionales de carácter reflexivo analizadas (en sí mismo, por sí mismo, para sí mismo y consigo mismo), en todos los periodos suelen predominar los grupos por sí mismo y en sí mismo (que denotan independencia e inherencia, respectivamente), aunque se dan diferencias 
significativas entre siglos. Como se puede apreciar en la Gráfico 2, en los siglos XVI y XVII, predomina por sí mismo seguido muy de cerca por en sí mismo; del siglo XVIII a la primera mitad del siglo XX, se acentúa el predominio de por sí mismo, aunque su empleo decrece del 70,6 \% en el siglo XVIII, al 47\% en el siglo XX. Por otra parte, la expresión preposicional de inherencia en sí mismo se emplea más en el siglo XVII que en otros periodos; la expresión de independencia por sí mismo es más frecuente relativamente en el siglo XVIII; la expresión de auto-referencia o reflexividad para sí mismo se da más en el siglo XVI que en otros siglos; por último, la expresión de intimidad consigo mismo se emplea más en el siglo XIX que en los otros periodos. En ese sentido, cabe sostener que hay diferencias significativas en la determinación sincategoremática de lo que es el caso y en la modulación de la mismidad, dependiendo del periodo histórico contemplado.

Gráfico 2. Porcentaje de empleo de las expresiones "en sí mismo", "por sí mismo", " para sí mismo" y "consigo mismo", entre 1500 y 1950, respecto al total de construcciones preposiciones reflexivas

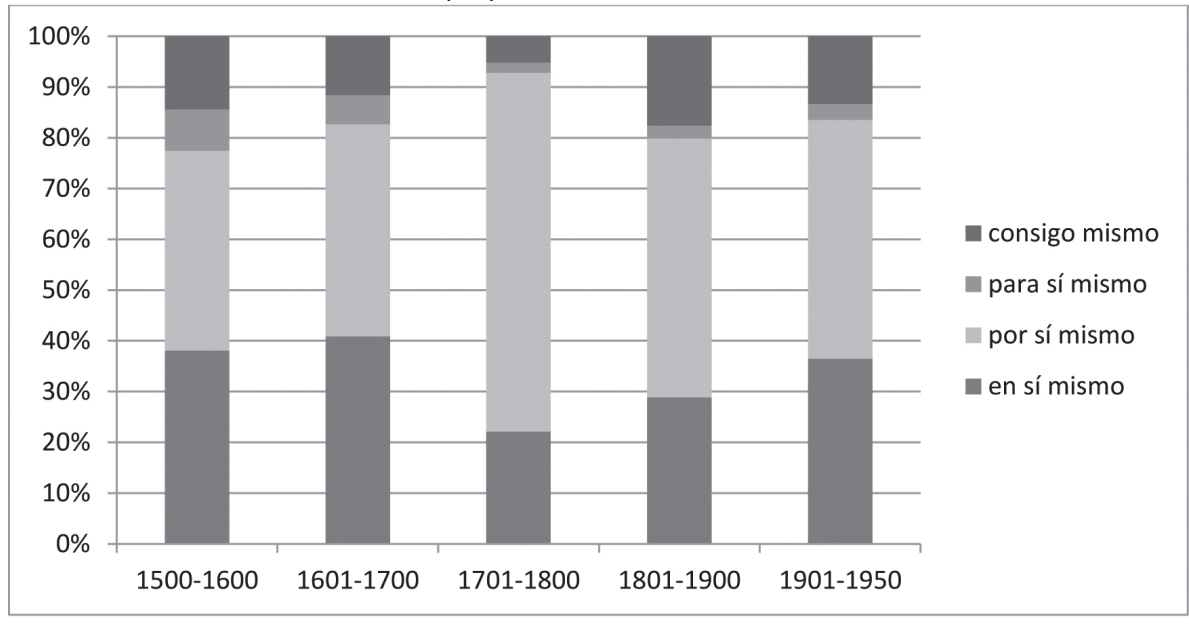

Fuente: elaboración propia.

$$
\chi^{2}=334.5859, \mathrm{p}<2.2 \mathrm{e}-16
$$

Si se agrupan todas las expresiones preposicionales reflexivas que expresan cierta mismidad o autidad (en sí mismo, por sí mismo, para sí mismo y consigo mismo) y se compara su frecuencia de empleo con la construcción preposicional entre sí de interdependencia, entre 1500 y 1950 cabe reconocer una disminución en el empleo de la expresión de relación o comunidad entre sí y un aumento de la utilización de las construcciones preposicionales que expresan mismidad o autidad, como se observa en la Gráfico 3. 
Gráfico 3. Porcentaje de empleo de las expresiones preposicionales de mismidad o autidad ("en sí mismo", "por sí mismo", "para sí mismo" y "consigo mismo"), en comparación con el uso de la construcción preposicional de interdependencia o comunidad ("entre sí"), entre 1500 y 1950



Fuente: elaboración propia.

$$
\chi^{2}=415.7744, \mathrm{p} \text {-value }<2.2 \mathrm{e}-16
$$

\section{Discusión y conclusiones}

Pese a los intentos filosóficos de aprehender la estructura última de la realidad, en forma de un repertorio de categorías fundamentales, obtenemos una panorámica bastante distinta de los nexos de sentido del ser, cuando nos hacemos cargo de los matices discursivos que introducen algunos determinantes sincategoremáticos —filosóficamente relevantes- en una comunidad idiomática específica como la hispanohablante. Lejos de avalar la idea de que el pensamiento y el discurso humano están enmarcados por categorías básicas o conceptos fundamentales fijos, en la comunidad hispanohablante moderna las abundantes comparaciones contrafácticas — como si- nos enfrentan a un tipo de construcción discursiva de la realidad eminentemente ficcional, que prima sobre las expresiones preposicionales determinativas de inherencia, independencia y relación. El discurso de la moderna comunidad hispanohablante parece asumir en mayor medida que lo que hay es una ficción o construcción como si, en lugar de estructurar la realidad del ser humano como un repertorio de entidades autorreferentes (en sí mismas, por sí mismas) o relacionadas (entre sî). Por lo demás, la ficcionalización o determinación ficcional de cuanto hay no es una rémora histórica que el curso de la modernización permitiera superar; por el contrario, la modernidad avanzada parece incrementar la ficcionalización de la experiencia. Este auge de lo ficticio en el siglo XX ya había sido caracterizado por Odo Marquard como una manera de lograr ficciones convenientes en un 
momento histórico en que, debido a la aceleración del cambio histórico, se hace cada vez más necesaria la reducción de la complejidad, aunque sea a través de la predisposición para la ilusión (Marquard, 2000, pp. 98-99).

Cuando nos preguntamos qué implica la tendencial disminución de las expresiones preposicionales determinativas de relación (entre sî́) y el aumento sostenido de las expresiones de mismidad o autidad (en sí mismo, por sí mismo, para sí mismo y consigo mismo), cabe sostener que la comunidad hispanohablante moderna parece haber transitado progresivamente desde una construcción discursiva de la realidad humana en que primaba la interdependencia, la reciprocidad y la comunidad, hasta un tipo de construcción discursiva de entidades individualizadas y auto-referentes, auto-contenidas e independientes, aunque no necesariamente más reflexivas. En ese sentido, la modernidad estructurada en la construcción discursiva de la comunidad hispanohablante no es la época de un sujeto auto-reflexivo y cada vez más autoconsciente, sino el despliegue histórico de un individualismo ontológico en que la realidad humana se perfila como un conjunto de mónadas auto-contenidas y auto-subsistentes (Dumont, 1987). Esta progresiva individualización auto-referencial de los universos de discurso de la moderna comunidad hispanohablante resulta concordante con las formas de privatismo, intimidad y auto-subsistencia que acompañan a los procesos de modernización, así como a la fragmentación de la esfera pública y al repliegue de las formas tradicionales de comunidad en la modernidad avanzada (Lasch, 1999; Lipovetsky, 1994; Taylor, 1994).

¿Cómo interpretar la diferencia histórica mostrada por la comunidad hispanohablante en el empleo de las expresiones preposicionales reflexivas y determinativas del sí mismo (en sí mismo, por sí mismo, para sí mismo y consigo mismo)? Para procurar una instancia mediadora entre los contextos socio-históricos de la comunidad hispanohablante y la organización gramatical del discurso o la estructura de la lengua natural, vamos a servirnos de la idea de que existen distintos regímenes de significación y modos de organización semiótica de la cultura. Se trata de un planteamiento defendido por la Escuela de Tartu, y que permitió a Lotman (1979) abordar las culturas históricas como modos de garantizar la comunicación significativa en una comunidad, o formas de modelizar el mundo y la sociedad, así como de preservar su memoria. Según el tipo de organización semiótica de la cultura, Lotman pudo identificar cuatro esquemas culturales posibles, que correspondían a distintos contextos históricos de la sociedad rusa. La cultura medieval realizaba primordialmente el tipo simbólico, basado en una codificación semántica y en la construcción discursiva de la realidad humana como entramado simbólico de significaciones. La época del absolutismo respondía al tipo cultural básicamente sintagmático, en que se lleva a cabo una exhaustiva codificación y reordenamiento cultural en que los significados locales se desdibujan dentro del conjunto estructural ordenador del Estado o la Iglesia. La época de la Ilustración, realizaría un tipo aparadigmático y asintagmático de organización cultural, en que 
prima la afirmación del individuo singular y el objeto natural, en desmedro de todo conjunto simbólico o regulación y codificación artificiales. Por último, la cultura burguesa del siglo XIX dio forma a un tipo cultural sintagmático y paradigmático, en que prima la organización semántica del sentido conjunto de los procesos históricos, pero también se apuesta por la sistematización ideal de los momentos particulares y de los individuos singulares como parte de la vida de los pueblos, las clases o la humanidad (Lotman, 1979).

Si adoptamos el modelo teórico de Lotman y suponemos que se puede extrapolar a los contextos socio-históricos de organización cultural de la comunidad hispanohablante, tal vez podamos identificar un tipo cultural renacentista —aún sometido parcialmente a los entramados simbólicos del medioevo-, que articularía sus universos de discurso, recurriendo a nexos de sentido ficcionales y a un tipo de determinación sincategoremática centrada en la comunidad y la interdependencia; pero este tipo renacentista también organiza la determinación reflexiva de los significados de la realidad humana a través de cierto equilibrio entre la inherencia y la independencia de lo que es en sí mismo y es por sí mismo, al tiempo que le da más cabida que otras épocas a la auto-referencia reflexiva del ser para sí mismo. Cabría reconocer un tipo cultural del Imperio, la Contrarreforma y el Barroco, cuya principal diferencia con el orden renacentista no radica solo en la recodificación sintagmática de los grandes conjuntos institucionales y doctrinales, así como en el exceso formal y sobrecarga compositiva, sino también en cierta determinación sincategoremática de los universos de discurso, que remarca la inherencia de lo que es en sí mismo y por sí mismo; semejante modulación de lo esencial inherente constituye el reverso de la sobrecodificación, sobrecarga formal y celo doctrinal de la época. Por otra parte, en la organización de los universos de discurso de la comunidad hispanohablante del siglo XVIII se puede reconocer la organización aparadigmática y asintagmática de la Ilustración, caracterizada por una caída relativa de los nexos simbólicos y las analogías ficcionales —la construcción discursiva como si-; además, este tipo ilustrado exhibe un desgaste de la referencia esencialista a lo que es en sí mismo, así como se da un marcado auge de la determinación de lo que es por sí mismo, es decir, una desnuda afirmación de la independencia y de lo que es auto-subsistente. En cuanto a realización la cultura burguesa del siglo XIX en la comunidad hispanohablante, el tipo sintagmático y paradigmático de construcción histórica de las nuevas culturas nacionales, así como la expresión articulada del sentido de los pueblos y clases sociales, se asocian a un tipo de determinación sincategoremática que restituye los nexos simbólicos ficcionales y, al mismo tiempo, le asigna un mayor lugar a la determinación reflexiva de la intimidad del ser consigo mismo. ¿Qué podemos decir con respecto a la primera mitad del siglo XX? Tal vez constituye una intensificación — modernista - del tipo cultural de la sociedad burguesa decimonónica, y no solo sigue marcado por la determinación reflexiva de la intimidad del estar consigo mismo, sino que además ve avanzar una re-esencialización de los universos de discurso como conjuntos de entidades auto-contenidas en sí mismas. Pero lo más 
llamativo de esta forma modernista de determinación del sí mismo contemporáneo en la comunidad hispanohablante consiste en que la modulación del sentido de inherencia e intimidad tiene como contrapartida una disminución tanto de la independencia o determinación por sí mismo, como de la interdependencia y relación entre sí, a la vez que se da un marcado auge de lo ficticio y de la construcción discursiva como si. Aparentemente, en la construcción discursiva de la comunidad hispanohablante se fue abriendo camino un tipo modernista de sí mismo sin atributos.

Se podría pensar que una reconstrucción de nexos de sentido como la emprendida en este estudio resulta desmedidamente ambiciosa, pues se pretendió dar cuenta de la construcción discursiva de la realidad en la moderna comunidad hispanohablante tan solo a partir de un repertorio acotado de expresiones sincategoremáticas. A lo cual solo cabe responder afirmativamente: en efecto, a partir de un repertorio limitado de determinantes preposicionales y de la construcción comparativa como si -y por muy relevantes que hayan sido estas expresiones en nuestra tradición filosófica-, no se pueden reconocer nada más que ciertas articulaciones parciales, fragmentarias, históricas y locales, del modo en que se construyen los nexos de sentido en una comunidad idiomática particular. Si se logró algo semejante, tal vez resulte suficiente y, en todo caso, parece más prudente que pretender dar cuenta de la estructura última de la realidad, a través de un repertorio de categorías presuntamente fijas, rígidamente jerarquizadas y lógicamente auto-consistentes $\Phi$

\section{REFERENCIAS}

Alemán Pardo, A. (1985). Teoría de las categorías en la Filosofía analítica. Madrid: Tecnos.

Arendt, H. (1997). ¿Qué es la política? Barcelona: Paidós.

Aristóteles (1999). "Categorías". En Aristóteles y Porfirio, Categorías. De interpretatione. Isagoge (pp. 67-146). Madrid: Tecnos.

Aristóteles (2000). Metafísica. Madrid: Gredos.

Aubenque, P. (1974). El problema del ser en Aristóteles. Madrid: Taurus.

Bardin, L. (1996). Análisis de contenido. Madrid: Akal

Beuchot, M. (1991). "La sustancia en Santo Tomás y algunas críticas de la filosofía analítica". Convivium, 2 (2), 19-27. 
Bochenski, J. M. (1985). Historia de la Lógica formal. Madrid: Gredos.

Brentano, F. (2007). Sobre los múltiples significados del ente según Aristóteles. Madrid: Encuentro.

Buber, M. (1967). ¿Qué es el hombre? México, D. F.: Fondo de Cultura Económica.

Butcharov, P. (2009). "Categories". En Kim, J., Sosa, E., \& Rosenkrantz, G. S. (Eds.), A Companion to Metaphysics (pp. 171-174). Oxford: Wiley-Blackwell.

Cassirer, E. (1993). Kant, vida y doctrina. Madrid: Fondo de Cultura Económica.

Copleston, F. C. (2000). El pensamiento de Santo Tomás. México, D. F.: Fondo de Cultura Económica.

Desmond, W. (2008). God and the Between. Oxford: Blackwell Publishing.

Dumont, L. (1987). Ensayos sobre el individualismo. Madrid: Alianza Editorial.

Kant, I. (2002). Crítica de la razón pura. Madrid: Alfaguara.

Hegel, G. W. F. (1985). Fenomenología del espíritu. Madrid: Fondo de Cultura Económica.

Havelock, E. (2002). Prefacio a Platón. Madrid: Antonio Machado.

Heidegger, M. (1960). "La época de la imagen del mundo". En Sendas perdidas (pp. 68-99). Buenos Aires: Losada.

Heidegger, M. (1985). La pregunta por la cosa. Madrid: Orbis.

Heidegger, M. (1987). "El habla". En De camino al habla (pp. 9-31). Barcelona: Ediciones del Serbal.

Heidegger, M. (1996). Kant y el problema de la metafísica. México, D. F.: Fondo de Cultura Económica.

Hyppolite, J. (1974). Génesis y estructura de la "Fenomenología del espíritu" de Hegel. Barcelona: Península.

Körner, S. (1970). Categorial Frameworks. New York: Barnes \& Noble.

Lasch, C. (1999). La cultura del narcisismo. Santiago de Chile: Andrés Bello. 
Lipovetsky, G. (1994). El crepúsculo del deber. Barcelona: Anagrama.

Lotman, J. M. (1979). "El problema del signo y del sistema sígnico en la tipología de la cultura anterior al siglo XX". En Lotman, J. M. y Escuela de Tartu, Semiótica de la Cultura (pp. 41-66). Madrid: Cátedra.

Lowe, E. J. (2006). The Four-Category Ontology. A Metaphysical Foundation for Natural Science. New York: Oxford University Press.

Marquard, O. (2000). “¿La época del extrañamiento respecto del mundo? Una contribución al análisis del presente". En Apología de lo contingente (pp. 89-108). Valencia: Alfons el Magnànim.

Platón (2007). Diálogos V. Parménides-Teeteto-Sofista-Político. Barcelona: RBA.

Porfirio (1999). "Isagoge". En Aristóteles y Porfirio, Categorías. De interpretatione. Isagoge (pp. 11-66). Madrid: Tecnos.

Real Academia Española (2010). Nueva gramática de la lengua española. Manual. Buenos Aires: Espasa Calpe.

Real Academia Española (2015). Corpus diacrónico del español. Recuperado de: http://www.rae.es

Ryle, G. (2005). El concepto de lo mental. Barcelona: Paidós.

Ryle, G. (2009). "Categories". En Collected Essays 1929-1968, Volume 2 (pp. 178193). London: Routledge.

Sartre, J. P. (1982). "El ser y la nada". En Obras completas, tomo III (pp. 1-510). Madrid: Aguilar.

Smart, J. J. C. (1953). "A Note on Categories". British Journal for the Philosophy of Science, 4 (15), 227-228.

Strawson, P. F. (1996). Individuals. An Essay in Descriptive Metaphysics. London: Routledge.

Strawson, P. F. (1997). Analisis y metafísica. Barcelona: Paidós.

Taylor, C. (1994). La ética de la autenticidad. Barcelona: Paidós.

Vaihinger, H. (1924). The Philosophy of "As if". London: Routledge. 